Article

\title{
Large Scale Landform Mapping Using Lidar DEM
}

\section{Türkay Gökgöz * and Moustafa Khalil M. Baker}

Department of Geomatic Engineering, Faculty of Civil Engineering, Y1ldız Technical University, Esenler, Istanbul 34220, Turkey; E-Mail: mustafa.eng@me.com

* Author to whom correspondence should be addressed; E-Mail: turkaygokgoz@ gmail.com; Tel.: +90-212-383-5341; Fax: +90-212-383-5102.

Academic Editors: Marinos Kavouras and Wolfgang Kainz

Received: 1 May 2015 / Accepted: 31 July 2015 / Published: 7 August 2015

\begin{abstract}
In this study, LIDAR DEM data was used to obtain a primary landform map in accordance with a well-known methodology. This primary landform map was generalized using the Focal Statistics tool (Majority), considering the minimum area condition in cartographic generalization in order to obtain landform maps at 1:1000 and 1:5000 scales. Both the primary and the generalized landform maps were verified visually with hillshaded DEM and an orthophoto. As a result, these maps provide satisfactory visuals of the landforms. In order to show the effect of generalization, the area of each landform in both the primary and the generalized maps was computed. Consequently, landform maps at large scales could be obtained with the proposed methodology, including generalization using LIDAR DEM.
\end{abstract}

Keywords: DEM; generalization; GIS; landform classification; LIDAR; minimum area

\section{Introduction}

Landform is often the most important factor in distinguishing between regions and an important element of geographic classification, typification, and regionalization. Edward H. Hammond [1,2] developed a macro landform classification procedure to identify landform types for the United States. This classification procedure has been used for mapping landforms around the world. Hammond's classification is quantitative in nature, with explicit definitions that can be easily applied by other researchers. Hammond's procedure combines three important parameters (i.e., slope, relief, and 
profile type) to identify different landform or terrain types. According to Hammond: Landform $($ terrain type $)=$ Slope + Relief + Profile. The combination of these attributes could provide as many as 96 landform units. Hammond determined that less than one-half of these are common in the United States, so he used only 45 units on his map. Hammond merged areas smaller than $2072 \mathrm{~km}^{2}$ into adjacent units so that he could generalize the information at the 1:5,000,000 scale of his published map. These landforms were subsequently grouped by Hammond into broader landform categories including nearly flat plains, rolling and irregular plains, plains with widely-spaced hills or mountains, partially dissected tablelands, hills, low mountains, and high mountains. Dikau et al. [3,4] attempted to apply Hammond's procedure in their landform classification of New Mexico using a geographic information system (GIS) that automates Hammond's manual procedures. Their main modifications were that they used no generalization procedures and included all 96 landform units in their analysis. They changed some of the unit terminology used by Hammond, modified the window movement, and established their own groupings of broader landform categories. A new process developed by Brabyn [5] partly resolves the problems with Dikau et al.'s classification process. This process has been applied to the whole of New Zealand, producing a classification that shows the macro landforms. Morgan and Lesh [6] implemented Hammond's model using the U.S. Geological Survey's 7.5 min, 30-meter resolution National Elevation Dataset (NED) with ArcGIS ModelBuilder and generated Dikau's versions of Hammond's landform maps. Gallant et al. [7] automated a method for mapping Hammond's landforms over large landscapes using digital elevation data. They compared their results against Hammond's published landform maps that were derived using manual interpretation procedures. Hrvatin and Perko [8] tested the suitability of Hammond's method for determining landform units in Slovenia. First, they took the original classification elements into account. Only thirteen of the twenty-one landform units specified by Hammond were selected. They suitably adapted Hammond's original method changing the form and size of the basic window and the boundaries between classification element classes. Nineteen landform units were thus identified in Slovenia using the adapted method. Merina et al. [9] obtained an automatic landform classification of the Alicante province (Spain) at 1:25,000 scale, and the result landform map was contracted with the real landform by pictures. Williams et al. [10] directly compared Morgan and Lesh's landform classes for areas shown in video views against the most common participant landform terms given for the same location.

The main objective of this study is to obtain landform maps at 1:1000 and 1:5000 scales by using GISs and LIDAR DEMs. Landform maps at 1:1000 and 1:5000 scales are derived from a primary landform map considering the "minimum area" condition in cartographic generalization. The primary landform map is obtained in accordance with Morgan and Lesh's methodology, except for the radius of the search window in the neighborhood operator and slope reclassification tool. Furthermore, an interface was developed for automation of the process.

\section{Methodology}

Input data is the LIDAR DEM with $0.25 \mathrm{~m}$ resolution. First, a buffer polygon is created around the borders of the study area. The buffer distance is specified such that it should be at least the circle radius value to be used as a search window parameter in the classification stage. In this study, since the circle radius was determined as 50 pixels, the buffer distance was computed as $50 \times 0.25=12.5 \mathrm{~m}$. 
The buffer is used to address the possible problem of edge matching from the view of landforms. In other words, it is used to obtain continuous landforms around the neighboring study areas. Then, the LIDAR DEM is clipped using a buffer polygon, i.e., extended borders of the study area. Using the clipped LIDAR DEM, a primary landform map is obtained in accordance with the methodology proposed by Morgan and Lesh [6], with some modifications (Section 2.2). The primary landform map is clipped using the borders of the study area. The clipped landform map is converted to a vector map. The polygon with the smallest area is determined in the vector map. Its value is compared to the value of the "minimum area" criterion in cartographic generalization. If the value of the smallest area in the landform map is greater than or equal to the value of the "minimum area", the landform map is suitable for the specified scale; if not, the Focal Statistics tool (Majority) is applied to the primary landform map to remove small regions while maintaining much of the original spatial pattern, and thus a generalized landform map is obtained. The generalized landform map is clipped using the borders of the study area. The clipped landform map is converted to a vector map and tested again with respect to the "minimum area" criterion. This process is repeated until the value of the smallest area in the landform map is greater than or equal to the value of the "minimum area." It should be noted that the test is performed on the clipped landform map rather than the buffered (i.e., primary) landform map, in order to make the correct decision regarding the smallest polygon just inside the study area. The flowchart in Figure 1 demonstrates the methodology of this study. Detailed explanations are given in the following sub-sections.

\subsection{Data Source}

A very high resolution ( $0.25 \mathrm{~m}$ cell size) LIDAR DEM was the main input data for this study (Figure 2). A standard topographic map sheet at 1:1000 scale (F21-a-20-c-4-b) of a region located near Yeniköy, Eyüp, Istanbul, Turkey was selected as the study area. It is comprised of 2808 rows and 2134 columns (i.e., 5,992,272 grid cells) and was produced in 2013. The minimum and maximum elevations in the study area are $13.66 \mathrm{~m}$ and $44.88 \mathrm{~m}$, respectively. The main characteristic of this area is that there are several former quarries which are now artificial lakes shows in darker blue, as shown in Figure 2. Since they appeared as flat or nearly flat plains in the landform map, it gives us a considerable advantage in validating of the results of this study. This is the reason we selected this region as the study area. Data was provided by the Istanbul Metropolitan Municipality.

\subsection{Classification Method}

The method developed by Morgan and Lesh [6] (with some modifications) was used in the landform classification. Many pixels with NoData occurred in the resulting landform map when a radius value of 20 pixels was used for the neighborhood (in accordance with Morgan and Lesh's method). Through trial and error, a radius value of 50 pixels was found to be appropriate. All pixels in the resulting landform map had no value with NoData only when the radius value of 50 pixels was used for the neighborhood. In addition to the automation of Morgan and Lesh's workflow, an interface was developed so that some of the parameters in the model could be changed by the user. 


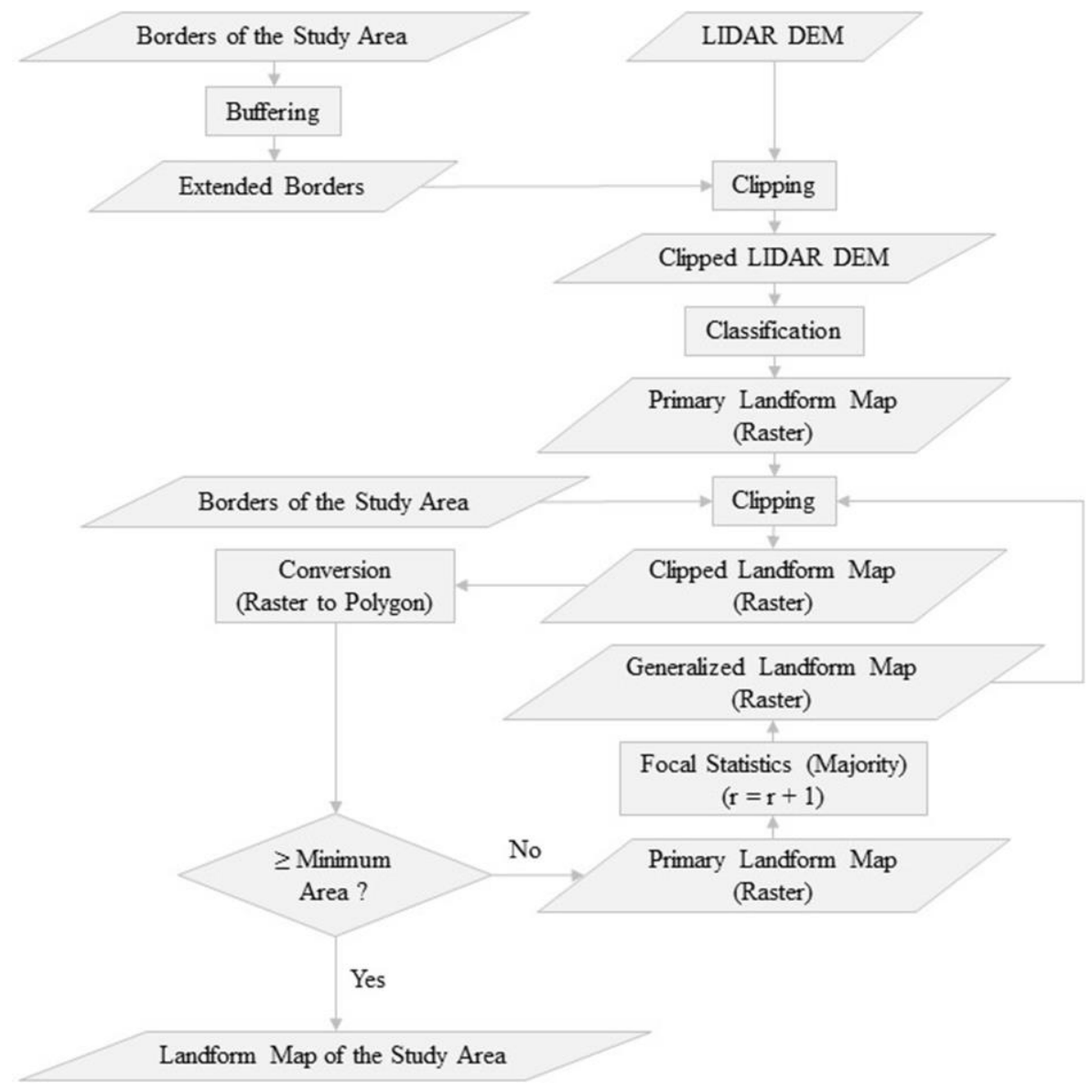

Figure 1. Flowchart of the methodology.

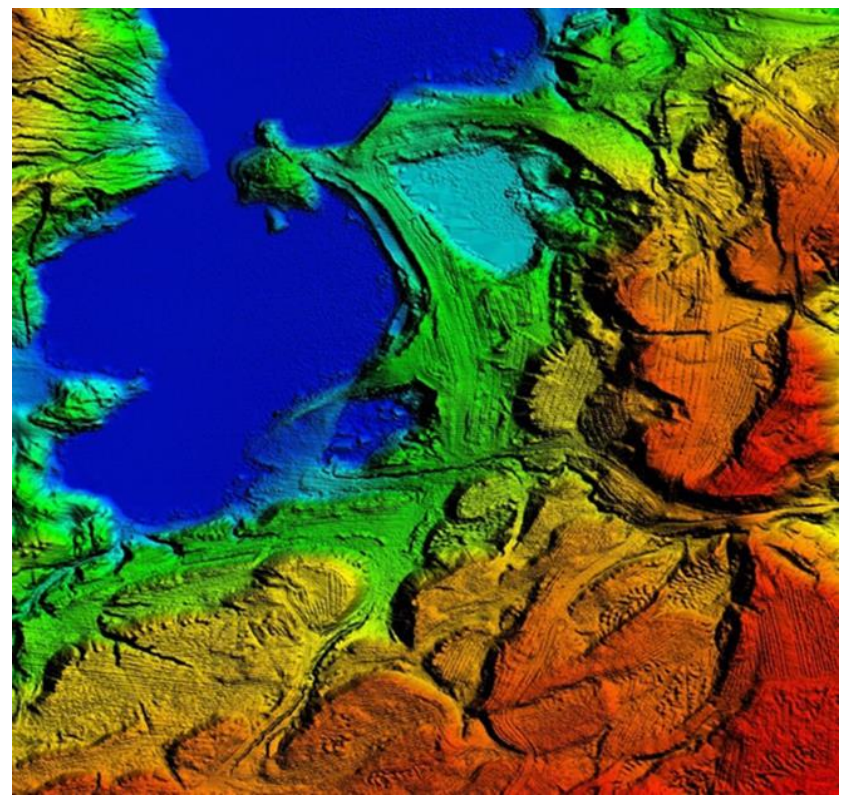

Figure 2. LIDAR DEM with $0.25 \mathrm{~m}$ resolution of the study area.

In order to make the slope threshold a model parameter in the interface, a logical tool (Greater Than) was used instead of the slope reclassification tool in Morgan and Lesh's model.

In accordance with the workflow of Morgan and Lesh's methodology, the analysis is split into three sub-sections: slope, relief, and profile, the results of which are then combined to form the final 
landform classification. The slope map gives the percentage of near-level land for each pixel (which is the value calculated for a 50 pixel radius circular neighborhood and a near-level threshold of $8 \%$ slope), split into four classes. The relief map gives the change in elevation for each cell based on the maximum and minimum elevation within a 50 pixel radius circular neighborhood. The profile map gives the percentage of near-level ground in upland and lowland areas of the landscape, again with a 50 pixel radius circular neighborhood. The boundary between upland and lowland is defined as the midpoint between the maximum and minimum elevation for the target pixel's neighborhood.

\subsection{Cartographic Generalization Condition: Minimum Area}

It is not practical to continue decreasing the size of map elements down to the barely perceptible and printable limits. The reasons for this are:

- Important objects should be immediately obvious, not just perceptible;

- The difference in form should be clearly distinguishable;

- Faint illumination and light printing colors reduce the contrast;

- The best reproduction and printing techniques and equipment are not always available or may not be economical.

Therefore, line widths and interspaces in minor landforms should not be less than the specified minimal dimensions. For topographic maps and black or very dark printing colors, the following value applies: a $0.3 \mathrm{~mm}$ side length of a solid square. Though small, a solid square this size can still be distinguished from a point [11]. Consequently, the number of pixels that approximately correspond to the minimum area at large and medium scales are computed with respect to the cell size of the source data in this study (i.e., $0.25 \mathrm{~m}$ ) (Table 1).

Table 1. Minimum area and corresponding number of pixels at each large and medium scale.

\begin{tabular}{ccc}
\hline Scale & Minimum Area $\left(\mathbf{m}^{\mathbf{2}}\right)$ & Number of Pixels \\
\hline $1: 1000$ & 0.09 & 2 \\
$1: 5000$ & 2.25 & 36 \\
$1: 10,000$ & 9.00 & 144 \\
$1: 25,000$ & 56.25 & 900 \\
$1: 50,000$ & 225.00 & 3600 \\
$1: 100,000$ & 900.00 & 14,400 \\
$1: 250,000$ & 5625.00 & 90,000 \\
\hline
\end{tabular}

The area of one pixel is $0.25 \times 0.25=0.0625 \mathrm{~m}^{2}$. The number of pixels corresponding to the minimum area at $1: 1000$ is $0.09 \div 0.0625=1.44$. However, since the clipped landform map (raster) is converted to a vector map setting the simplify parameter as NO_SIMPLIFY, pixel-based polygon areas are computed. Therefore the number of pixels corresponding to the minimum area at 1:1000 is assumed to be 2 as the nearest greater value to a computed value of 1.44 . On the other hand, the number of pixels corresponding to the minimum area at 1:5000 is computed as $2.25 \div 0.0625=36$ directly. Consequently, $2 \times 0.0625=0.125 \mathrm{~m}^{2}$ and $36 \times 0.0625=2.25 \mathrm{~m}^{2}$ are used as thresholds, i.e., values of the minimum area criterion, in the test mentioned in the methodology. 


\section{Results and Discussion}

The minimum area value in the primary landform map was $0.0625 \mathrm{~m}^{2}$, which was smaller than the threshold, i.e., the value of minimum area criterions $0.09 \mathrm{~m}^{2}$ and $2.25 \mathrm{~m}^{2}$ for both 1:1000 and 1:5000 scales. Landform maps at 1:1000 and 1:5000 were obtained by generalizing the primary landform map. When the trails reached four circle neighborhoods in the Focal Statistics (Majority) process for generalization of the primary landform map, the minimum area value in the clipped landform map was $1.1875 \mathrm{~m}^{2}$, which was the nearest greater value to a computed value of $0.09 \mathrm{~m}^{2}$. Thus, a suitable landform map at 1:1000 was obtained. Similarly, when the trails reached nine circle neighborhoods in the Focal Statistics (Majority) process for generalization of the primary landform map, the minimum area value in the clipped landform map was $3.125 \mathrm{~m}^{2}$, which was the nearest greater value to a computed value of $2.25 \mathrm{~m}^{2}$. Thus, a suitable landform map at 1:5000 was obtained (Table 2).

Table 2. Result landform maps and minimum areas.

\begin{tabular}{cc}
\hline Result Maps & Minimum Area $\left(\mathbf{m}^{\mathbf{2}}\right)$ \\
\hline Primary Landform Map & 0.0625 \\
Generalized Landform Map at 1:1000 & $1.1875(>0.0900)$ \\
Generalized Landform Map at 1:5000 & $3.1250(>2.2500)$ \\
\hline
\end{tabular}

In order to evaluate the results, i.e., verify the landforms visually, an orthophoto of the study area dated 2010 was used. The landform maps were confirmed by three dimensional views of the orthophoto and LIDAR DEM (Figure 3). Their hillshaded versions are also produced for the same purpose. The primary landform map with its hillshaded version are shown in Figure 4. The generalized landform maps at 1:1000 and 1:5000 with their hillshaded version are shown in Figure 5.

Of the 24 landform units specified by Morgan and Lesh, only four were distinguished in our study area: irregular plains with low relief open very low hills, very low hills, and flat or nearly flat plains. Since artificial lakes are above sea level, they were indicated as flat or nearly flat plains as well.

The areas of each landform type in the result maps are given in Table 3. The dominant landform in all result maps is open very low hills, followed by very low hills, and flat or nearly flat plains (which cover a large percentage of the study area). Irregular plains with low relief is the least prevalent landform.

Table 3. Area and percentage of each landform type in primary, 1:1000 and 1:5000 landform maps.

\begin{tabular}{ccccccc}
\hline \multirow{2}{*}{ Landform Type } & \multicolumn{2}{c}{ Primary Landform Map } & \multicolumn{3}{c}{ Generalized Landform Map } \\
\cline { 2 - 7 } & \multicolumn{2}{c}{$\mathbf{m}^{\mathbf{2}}$} & & $\mathbf{1 : 1 0 0 0}$ & \multicolumn{1}{c}{$\mathbf{1 : 5 0 0 0}$} \\
\cline { 2 - 7 } & $200,746.500$ & 46.46 & $200,806.688$ & 46.47 & $201,082.750$ & 46.54 \\
Open Very Low Hills & $138,289.625$ & 32.00 & $138,264.875$ & 32.00 & $138,146.250$ & 31.97 \\
Very Low Hills & $62,359.938$ & 14.43 & $62,365.188$ & 14.43 & $62,375.188$ & 14.44 \\
Flat or Nearly Flat Plains & $30,700.250$ & 7.11 & $30,660.250$ & 7.10 & $30,493.500$ & 7.05 \\
\hline Irregular Plains with Low Relief & & & & & & \\
\hline
\end{tabular}




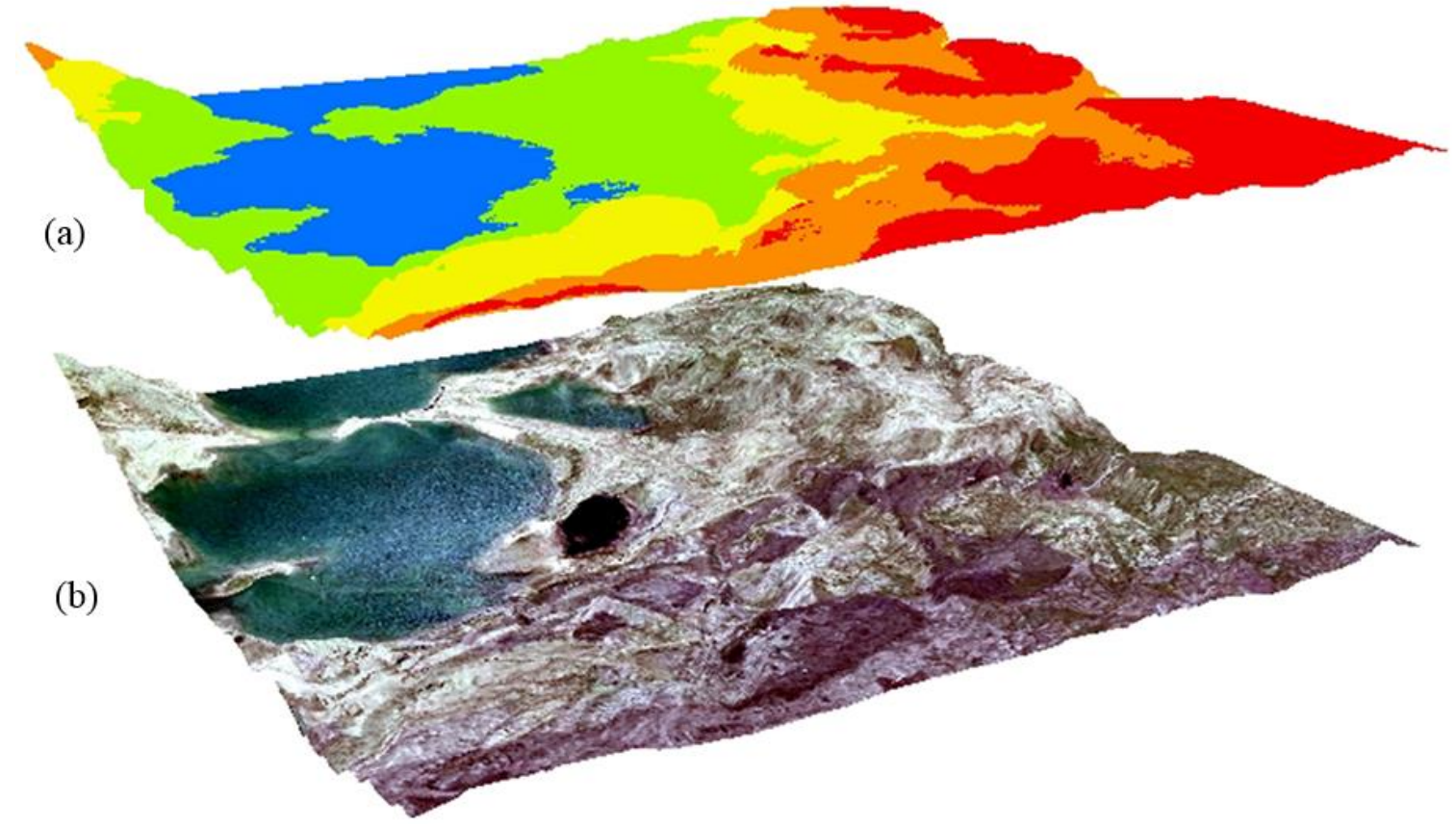

Figure 3. (a) LIDAR DEM; (b) Orthophoto.
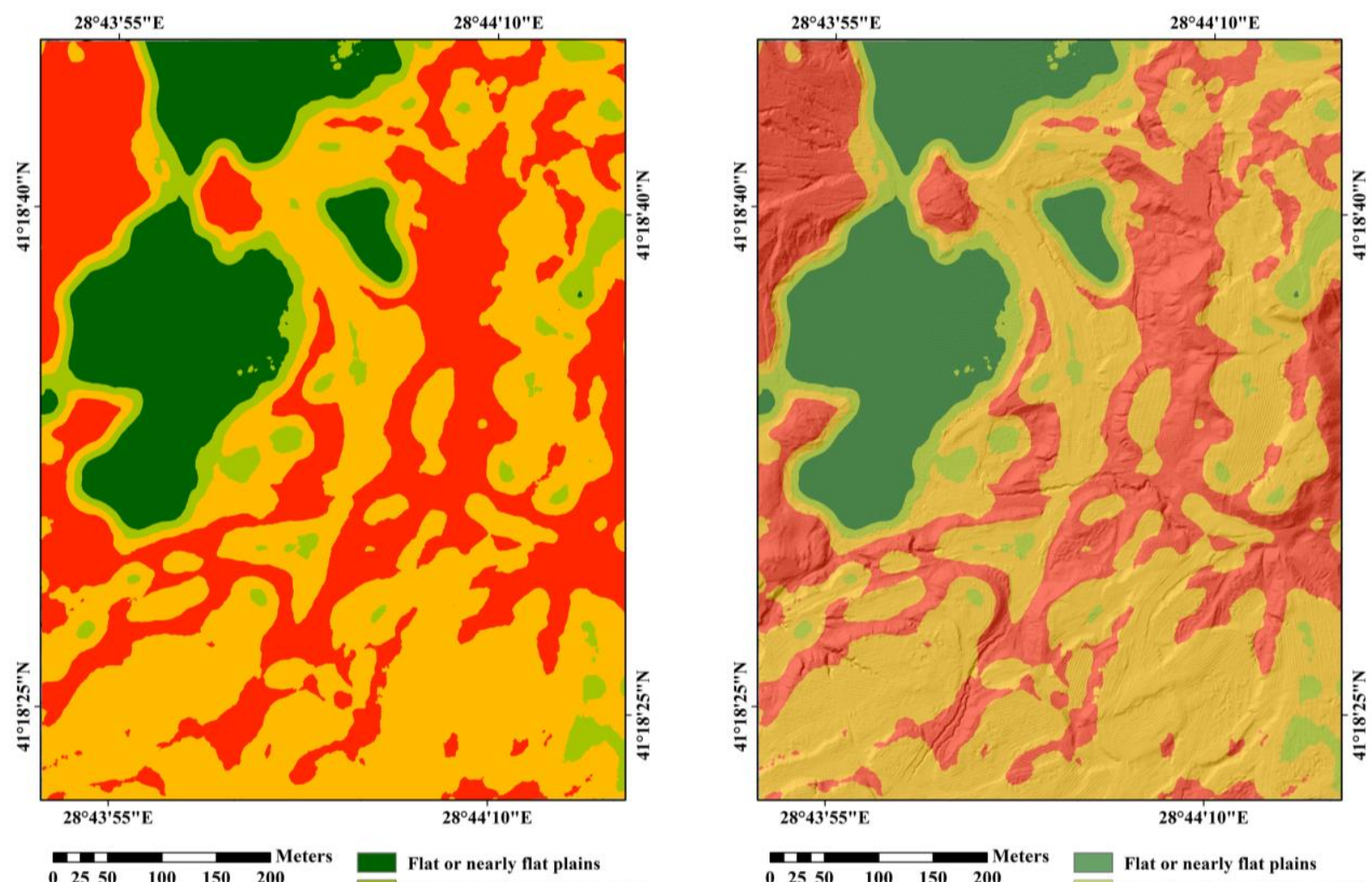

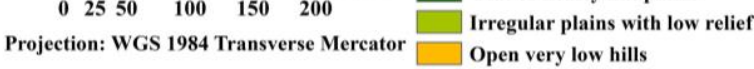
Very low hills

(a)



(b)

Figure 4. (a) Primary landform map; (b) Hillshaded primary landform map. 


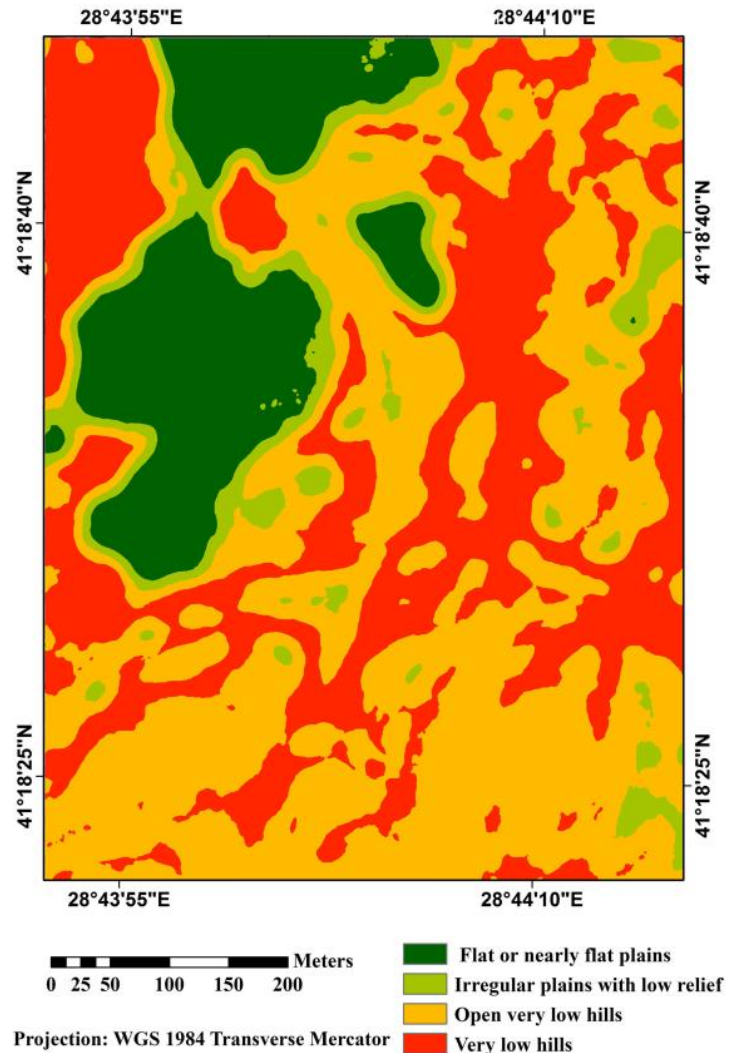

(a)

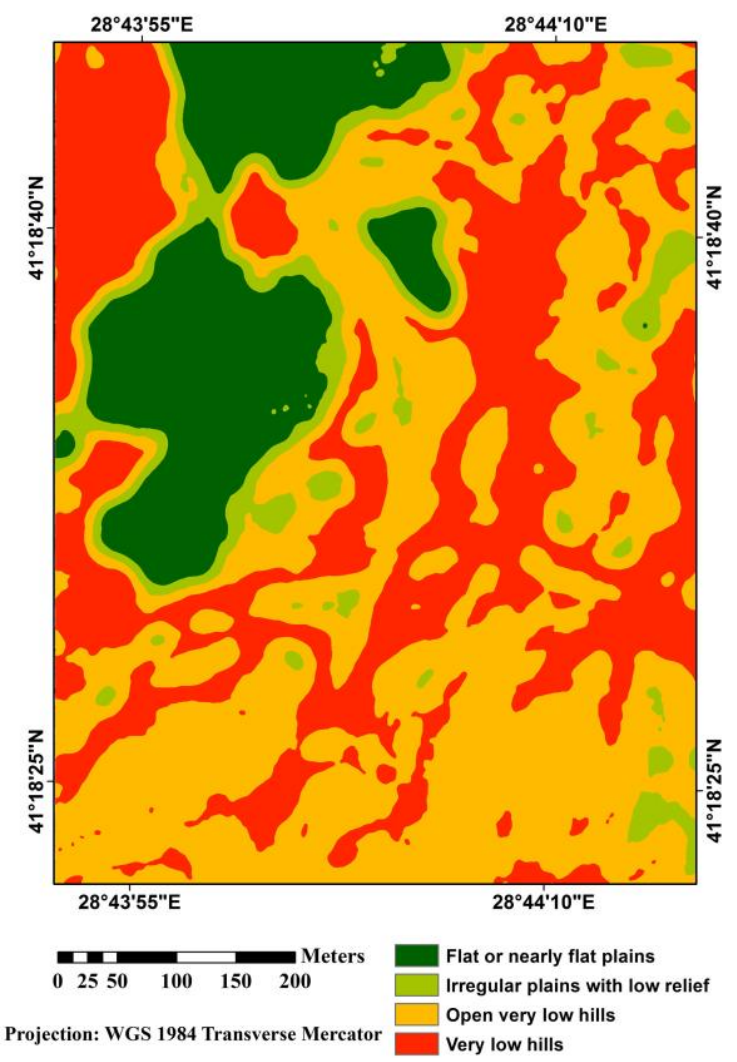

(c)

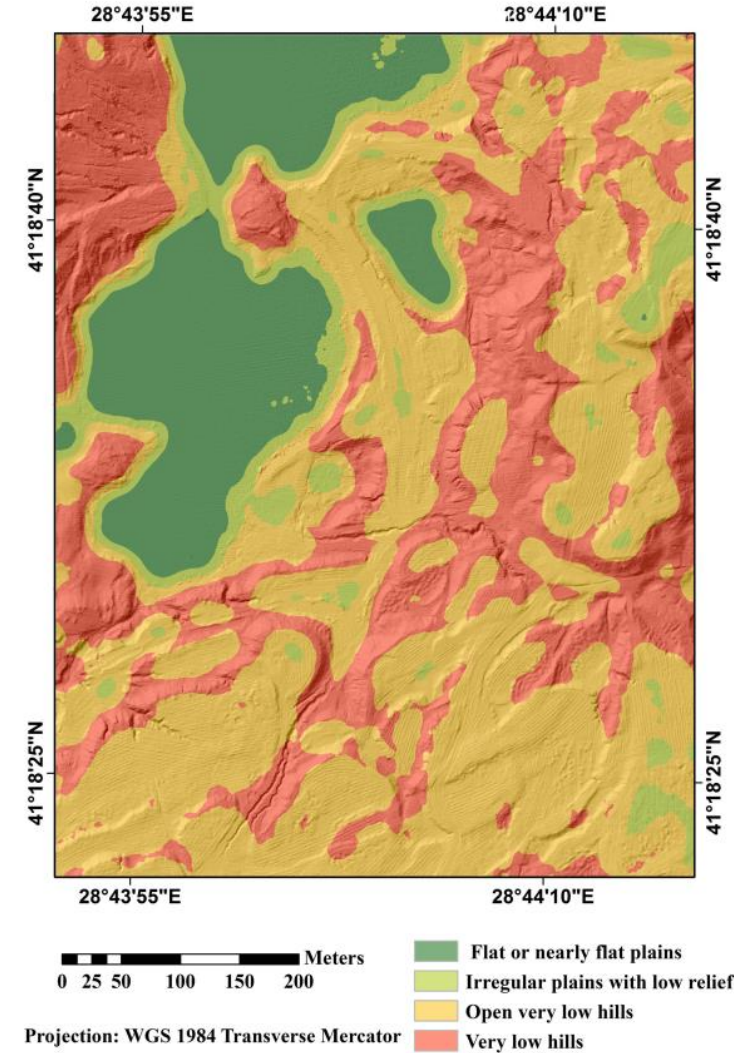

(b)

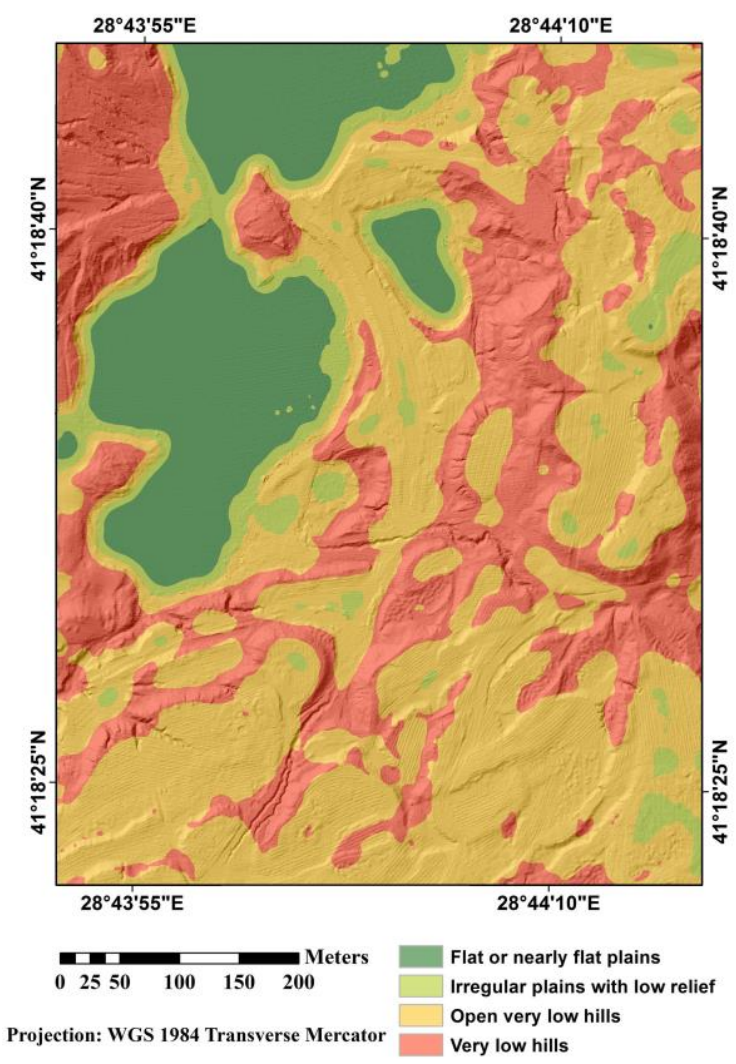

(d)

Figure 5. (a) Generalized landform map at 1:1000; (b) Hillshaded generalized landform map at 1:1000; (c) Generalized landform map at 1:5000; (d) Hillshaded generalized landform map at 1:5000. 


\section{Conclusions}

LIDAR DEM data could be used to obtain landform maps at large scales due to its high resolution. Since LIDAR DEM data produces very detailed landforms, a generalization process is necessary for deriving landforms at specified scales. The generalization process could be managed by amalgamating smaller areas recursively. Minimum sizes in cartography could be used as a threshold in the amalgamation process. There is no fixed search window size that is valid for all applications in areas of all sizes with any DEM resolution. The search window size must be determined for each study, depending on the area covered and the DEM resolution. However, the user should keep in mind that increasing the size of the search radius will in turn increase the time required to process the model.

Furthermore, as was the case in this study, there may be a limited range of topographic features due to limited elevation, slope, relief, or profile. The final landform classification map does not indicate landform elements such as artificial lakes. An additional note regarding the successful use of Morgan and Lesh's method is that care must be taken to avoid changing missing values to NoData during the reclassification steps and ignore NoData in calculations during Focal Statistics steps.

\section{Acknowledgments}

We would like to appreciate Turkey Scholarship for supporting and giving an opportunity to Moustafa Khalil M. Baker to complete M.Sc. degree in Y1ldız Technical University, Istanbul, Turkey.

\section{Author Contributions}

Türkay Gökgöz conceived of the study, wrote the paper and interpreted the results. Moustafa Khalil M. Baker designed the study, performed the experiments and analyzed the data.

\section{Conflicts of Interest}

The authors declare no conflict of interest.

\section{References and Notes}

1. Hammond, E.H. Small scale continental landform maps. Ann. Assoc. Am. Geogr. 1954, 44, $32-42$.

2. Hammond, E.H. Analysis of properties in landform geography: An application to broad scale landform mapping. Ann. Assoc. Am. Geogr. 1964, 54, 11-19.

3. Dikau, R.; Brabb, E.E.; Mark, R.M. Landform Classification of New Mexico by Computer. U.S. Geological Survey; US Geological Survey: Menlo Park, CA, USA, 1991.

4. Dikau, R.; Brabb, E.E.; Mark, R.M.; Pike, R.J. Morphometric landform analysis of New Mexico. Adv. Geomorphom. Z Geomorphol. 1995, 101, 109-126.

5. Brabyn, L. Classification of Macro and forms using GIS. ITC J. 1997, 1, 26-40.

6. Morgan, J.M.; Lesh, A. Developing landform maps using ESRI's model builder. In Proceedings of the 2005 ESRI International User Conference, San Diego, CA, USA, 25-29 July 2005. 
7. Gallant, A.L.; Brown, D.D.; Hoffer, R.M. Automated mapping of Hammond's landforms. IEEE Geosci. Remote. Sens. Lett. 2005, 2, 384-388.

8. Hrvatin, M.; Perko, D. Suitability of Hammond's method for determining landform units in Slovenia. Acta Geogr. Slov. 2009, 49, 343-366.

9. Merina, A.P.; Perucho, M.A.; Ruiz, M.A.; Guerrero, I.C. Landform of Alicante province by using GIS. In Proceedings of the 2011 International Conference on Innovative Methods in Product Design (IMProVe 2011), San Servolo, Venice, Italy, 15-17 June 2011.

10. Williams, M.; Kuhn, W.; Painho, M. The influence of landscape variation on landform categorization. J. Spat. Inf. Sci. 2012, 5, 51-73.

11. Rytz, A.; Bantel, E.; Hoinkes, C.; Merkle, G.; Schelling, G. Kartographische Generalisierung: Topographische Karten. In Kartographische Schriftenreihe Herausgegeben Von Der Schweizerischen; Schweizerische Gesellschaft für Kartographie: Bern, Switzerland, 1975; pp. 12-17.

(C) 2015 by the authors; licensee MDPI, Basel, Switzerland. This article is an open access article distributed under the terms and conditions of the Creative Commons Attribution license (http://creativecommons.org/licenses/by/4.0/). 